\title{
AGREEMENT AND REPRODUCIBILITY OF FIELD AND LABORATORY TESTS IN THE PREDICTION OF RUNNING SPEED IN A 10-KM RACE IN AMATEUR RUNNERS
}

\author{
Heitor Siqueira Ribeiro ${ }^{1,3}$, Hugo Luca Corrêa ${ }^{2}$, Lívia Kelly Barbosa Lima ${ }^{2}$, \\ Maria Barroso Costa Filha' ${ }^{2}$, Severino Leão Albuquerque Neto ${ }^{2}$, \\ Edilberto Santos Barros ${ }^{2}$, and Aparecido Pimentel Ferreira ${ }^{3}$ \\ ${ }^{1}$ Physical Education Faculty, University of Brasília, Brasília, Brazil \\ ${ }^{2}$ Physical Education Department, Catholic University of Brasilia, Brasília, Brazil \\ ${ }^{3}$ University Centre ICESP, Brasília, Brazil
}

Original scientific article

DOI: $10.26582 / \mathrm{k} .52 .2 .16$

\begin{abstract}
:
Knowing running speed, particularly by means of easy-to-apply tests and low cost, is important to the definition of race strategy and of the most appropriate training throughout the preparation period. The aim was to compare the agreement and reproducibility of critical velocity (CV), anaerobic threshold (AT), and the time trial on the track for the determination of the running speed in a $10-\mathrm{km}$ race in amateur runners. A cross-sectional study was conducted with 34 runners of both genders aged $42.4 \pm 11.0$ years. We measured their CV, assessed their body composition and AT. Participants also performed a simulated trial on a $10-\mathrm{km}$ running track and an official $10-\mathrm{km}$ race. The delta of the comparisons and the standard error of estimate between the running velocities determined by the $\mathrm{CV}$, AT, and the simulated time trial on the track ranged from 0.55 to $-0.79 \mathrm{~km} / \mathrm{h}$ and 0.14 to $0.59 \mathrm{~km} / \mathrm{h}$, respectively. Furthermore, CV and AT were compared to the $10-\mathrm{km}$ running speed. Good agreement and reproducibility were observed between the velocities determined by the $\mathrm{CV}$, AT, and the simulated time trial on the track with the real-time of a $10-\mathrm{km}$ official race.
\end{abstract}

Key words: critical velocity, anaerobic threshold, running, endurance

\section{Introduction}

Long-distance street running races have increased in popularity in recent years in several countries (Anthony, et al., 2014; Gómez-Molina, et al., 2017; Knechtle, Nikolaidis, Zingg, Rosemann, \& Rüst, 2016), especially among recreational practitioners, who aim to improve their physical fitness and health, but are also motivated by the achievement of better performances, which requires coaches and physical education professionals to identify the determining factors of performance enhancement (Santos, et al., 2012). Consequently, the interest of scientific community has been increased in studying different factors that may affect performance (Ogueta-Alday \& Gácia-López, 2015).

Some authors have so far presented a series of potential physiological variables traditionally investigated as predictors or determinants of performance in long-distance races, such as maximum oxygen uptake $\left(\mathrm{VO}_{2 \mathrm{MAX}}\right)$, anaerobic threshold (AT), critical velocity $(\mathrm{CV})$, running economy, maximum aerobic velocity, velocity associated with $\mathrm{VO}_{2 \mathrm{MAX}}$ and AT, among others (da Silva, Sotero, Simões, \& Machado, 2015; Denadai, Ortiz, Stella, \& Mello, 2003; Ogueta-Alday \& Gácia-López, 2015; T. M. Santos, et al., 2012; Smith \& Jones, 2001; Souza et al., 2014). However, due to the detriment of distance and duration of a race, performance seems to be influenced not only by the physiological variables, but also by anthropometric parameters, race strategy, age, gender, and supplementation strategy and they should also be considered (Santos, et al., 2017).

Santos et al. (2017) state that during races, endurance runners generally adopt different pacing strategies, such as either higher or lower speed in different moments. Nevertheless, some runners try to maintain the same rhythm from the beginning to the end of the race, which does not mean the same physiological demand, particularly due to the terrain relief, climate changes, and the accumulated strain throughout the race (Thiel, Foster, Banzer, $\&$ de Koning, 2012). Thus, it seems clear that the intensity of the race undergoes significant variations during events from medium- $(5,10$, or $15-\mathrm{km})$ to 
long-distance races (half- or full-marathons), which requires the interaction between different energy systems (Thiel, et al., 2012). In this sense, knowing running speed is interesting for the establishment of the best race strategy (Lima-Silva, et al., 2010) as well as for quality training designs; knowledge of running speed can also be used as a parameter for the definition of training intensities and volumes throughout the periodization.

Studies analyzed running speed during a $10-\mathrm{km}$ race and identified an association between physiological parameters and running speed (Bertuzzi, et al., 2014; Lima-Silva, et al., 2010), by both field methods and laboratory tests. Among the laboratory methods, the anaerobic threshold (AT) seems to be a good predictor of running speed because it represents the moment of transition from the predominance of aerobic energy production to the anaerobic energy production (Faude, Kindermann, \& Meyer, 2009 ) and has been described in some studies with runners (da Silva, et al., 2015; Souza, et al., 2014, 2011) since AT corresponds to an intensity of effort that can be maintained with a stable state of oxygen and lactate consumption (Wakayoshi, et al., 1992, 1992).

Regardless of the method, it seems clear that getting to know running speed is of vital importance, especially if the insight can be obtained by means of easy-to-apply, low-cost and accurate tests. So, the present study aimed to compare the agreement and reproducibility of critical velocity, anaerobic threshold, and the simulated time trial on the track for the prediction of running speed in a $10-\mathrm{km}$ official race in amateur runners. We hypothesized that the critical velocity and the trial on the track would be more efficient than the anaerobic threshold in predicting the $10-\mathrm{km}$ race speed in amateur runners.

\section{Methods}

\section{Sample and ethical criteria}

A cross-sectional study was conducted with a convenience sample of 34 runners, of both genders (20 males). The study was approved by the Research Ethics Committee of the Catholic University of Brasília - UCB and each participant signed an informed consent form.

\section{Inclusion criteria}

Amateur runners from a running club from Brasília, Brazil, were invited to participate in this study. The eligibility criteria were: to have participated in at least one $10-\mathrm{km}$ competition and being asymptomatic of any health problem. They should have uninterrupted training experience of at least six months, sign the informed consent form, participate in all study's tests, and not be taking any medication that could change their heart functions.

\section{General procedures}

The participants attended testing on four days and on one day they participated in an official $10-\mathrm{km}$ race. During their visits, the following tests were performed: i) body composition assessment and maximum treadmill test; (ii) 400-meter running track test; (iii) 2000 -meter running track test; (iv) $10-\mathrm{km}$ simulated time trial on the running track; and v) $10-\mathrm{km}$ run in an official race. The tests $\mathrm{i}$, ii, and iii were performed in a random order. All track tests were conducted on the official track under similar climatic conditions (air temperature $=21-26{ }^{\circ} \mathrm{C}$, relative humidity $=45-63 \%$ ), with at least 48 -hour interval between the tests. Athletes were instructed to participate in the study under conditions of total recovery, hydration, and nourishment. The experiment was completed in two weeks. Before each track test, the athletes were instructed to perform a moderate-intensity warm-up exercise followed by stretching.

\section{Body composition analysis}

Body fat was measured using dual-energy X-ray absorptiometry (DXA). Volunteers were asked to remove any metallic items they were wearing, such as rings, jewelry, belts, and watches (because such objects affect readings of the values of the estimated variables). Next, volunteers were placed in the horizontal decubitus dorsal position on the DXA apparatus for the full-body analysis. The equipment used was a Lunar DPX-IQ with version 4.6A software. Before using, the DXA equipment was duly calibrated, according to the manufacturer recommendations, and cut line adjustments were predefined. All analyses were performed by the same measurer.

\section{Maximum treadmill test}

A maximum treadmill test (MTT) was performed as an incremental exercise test with two-minute stages and increments of $0.5 \mathrm{~km} / \mathrm{h}$. The initial velocity was individualized between 8 and $9 \mathrm{~km} / \mathrm{h}$ on the treadmill (Brudden Equipments LTDA and Line Movement, model RT 400, São Paulo, BRA). These tests were performed at an air temperature maintained between 21 and $23^{\circ} \mathrm{C}$ and relative humidity between 40 and $60 \%$. The test was conducted until voluntary exhaustion or any other ending criteria such as blood pressure $\geq 260 / 115$ $\mathrm{mmHg}$, rating of perceived exertion (RPE) $>19$ on the Borg 6-20 scale, or S-T segment electrocardiogram with depression or elevation greater than 2 $\mathrm{mm}$. During each test, heart rate (HR) was measured continuously as well as blood pressure (BP), RPE, ventilation (VE), oxygen uptake $\left(\mathrm{VO}_{2}\right)$, carbon dioxide release $\left(\mathrm{VCO}_{2}\right)$, oxygen ventilation equivalent $\left(\mathrm{VE} / \mathrm{VO}_{2}\right)$, carbon dioxide equivalent (VE/ $\mathrm{VCO}_{2}$ ), and respiratory exchange ratio (RER). Each subject was instructed to avoid caffeine, alcohol, and strenuous exercise 48 hours before the experi- 
ments, as well as to eat normally and avoid foods not usual in their daily intake.

Maximum oxygen uptake $\left(\mathrm{VO}_{2 \mathrm{MAX}}\right)$ was determined using a breath-by-breath method (Cortex and Metalyzer 3B from Cortex Biophysik - GER) and it was valid when at least two of the following criteria were met: $\mathrm{RER}>1.15, \mathrm{VO}_{2}$ plateau $\Delta \mathrm{VO}_{2} \geq 150 \mathrm{ml}$ at the last minute, $\mathrm{HR}<10 \mathrm{bpm}$ of 220 and age, and/or $\mathrm{RPE} \geq 19$. Anaerobic threshold (AT) was determined based on $\mathrm{VE} / \mathrm{VO}_{2}$ and $\mathrm{VE} / \mathrm{VCO}_{2}$, measured at the point where $\mathrm{VE} / \mathrm{VO}_{2}$ increased disproportionately compared to the increase in $\mathrm{VE} / \mathrm{VCO}_{2}$ (Ferreira, et al., 2013).

The maximum treadmill test was used to determine the maximum heart rate (MHR) at the highest HR found in the test. Intensity at which the AT was used to determine the oxygen uptake at the AT $\left(\mathrm{AT}_{\mathrm{VO} 2}\right)$, running speed at the $\mathrm{AT}\left(\mathrm{AT}_{\mathrm{SPEED}}\right)$, heart rate at the $\mathrm{AT}\left(\mathrm{AT}_{\mathrm{HR}}\right)$, and rating of perceived exertion at the $\mathrm{AT}\left(\mathrm{AT}_{\mathrm{RPE}}\right)$.

\section{Critical velocity}

For the determination of the $\mathrm{CV}$, the times of the $400 \mathrm{~m}$ and 2,000 $\mathrm{m}$ tests on an official athletics track were recorded. Participants were instructed to run the set distances, alone, in the shortest possible time. The CV was calculated as the linear relation between distance and race time, corresponding to the slope of the linear regression line. The tests were performed at 08:00 a.m. or 7:00 p.m.

\section{0-km simulated time trial on the track}

The 10-km simulated time trial on the track took place on an official running track, with all involved in a single session, which began at 9:00 a.m. Each volunteer was identified, and a group of referees counted laps until completing $10-\mathrm{km}$. From the 5th lap, a table was placed with water next to the track, so the athletes could hydrate themselves. Hydration occurred ad libitum.

\section{0-km race}

The 10-km race chosen to compose this study was the Race of the Physical Education Professional, certified by the Brazilian Athletics Confederation, held in Brasilia-DF at approximately 1,080 meters above sea level. The race started at 07:00 a.m.; air temperature was $17.3^{\circ} \mathrm{C}$ and $53 \%$ relative humidity. The slope along the course was around -1.0 to $0.9 \%$. A timing system was used via a chip positioned in the sneakers of each runner.

\section{Statistical analysis}

Initially, the normality of the data was verified through the Shapiro-Wilk's test. Data are presented like mean and standard deviation. The independent t-test was used to compare the means according to gender. The paired t-test was used to compare the means of the $10-\mathrm{km}$ running speed with the $\mathrm{CV}$, AT, and the simulated time trial on the track. The BlandAltman plot was used to evaluate the concordances between the velocities established in the $10-\mathrm{km}$ race with the $\mathrm{CV}$, AT, and the simulated time trial on the track. The upper and lower limits of agreement for the Bland-Altman analysis were established with an alpha of $95 \%$ ( \pm 1.96 standard deviation). In order to evaluate the reproducibility between the velocities established in the $10-\mathrm{km}$ race with the $\mathrm{CV}, \mathrm{AT}$, and the simulated time trial on the track, the intraclass correlation coefficient (ICC) and the Cronbach's alpha were calculated. The ICC values were interpreted as poor if $<.40$, moderate if between .40 and .75 , and excellent if $>.75$, according to the scale of reliability levels proposed by Fleiss (1999). Also, the values of total error (ET), standard error of estimate (SEE), and absolute and relative delta were calculated. The value of $<.05$ was adopted to indicate significant differences. The SPSS program, version 18.0 was used for the analyses.
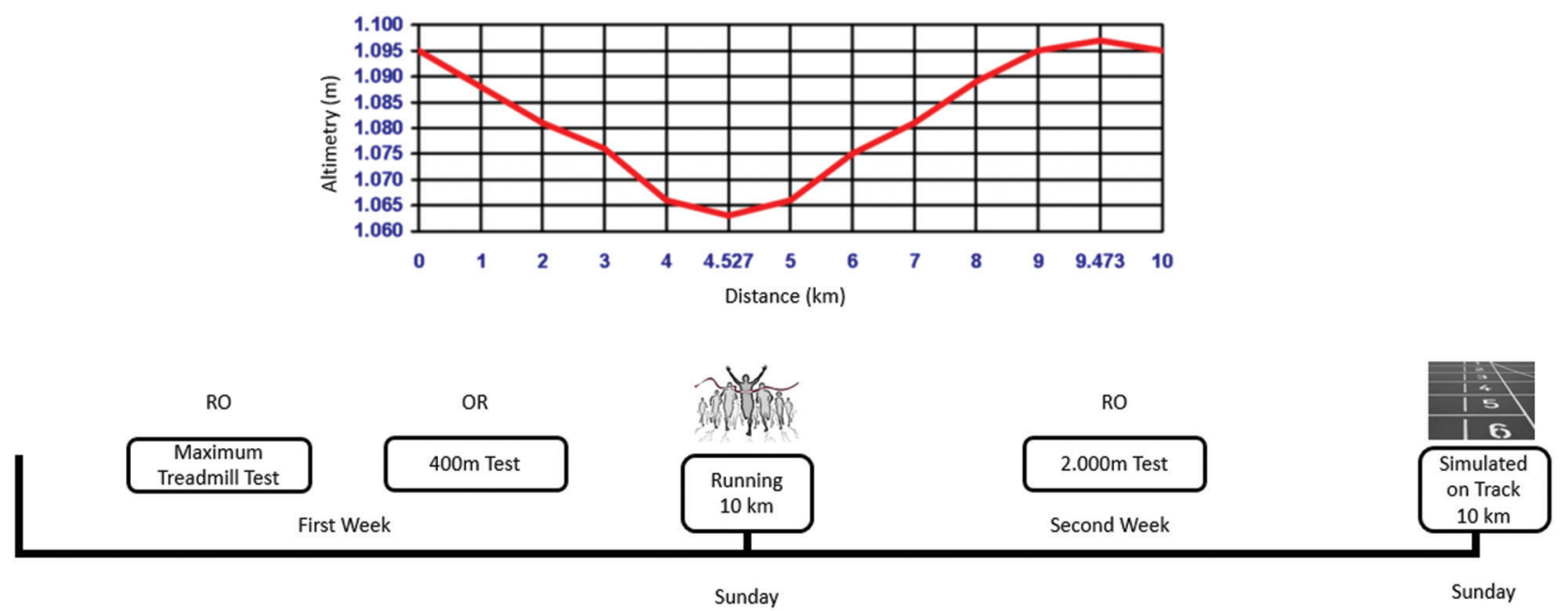

Figure 1. Schematic drawing of the study. 


\section{Results}

Table 1 shows the results of the characterization of the sample for the total group and stratified according to gender.

As seen in Table 1, only age, MHR, $\mathrm{AT}_{\mathrm{HR}}$, and $\mathrm{AT}_{\mathrm{SPEED}}$ did not differ between men and women.

Table 2 presents the values of mean velocity of the $10-\mathrm{km}$ race and of the simulated time trial on the track, as well as the AT and CV velocities determined in laboratory and field tests, respectively.

Only the velocities determined by the $\mathrm{CV}$ and the AT were similar to the time of the $10-\mathrm{km}$ race in women. The simulated time trial on the track differed from the $10-\mathrm{km}$ race velocity in the total group and both genders. For the total group and men, the $\mathrm{CV}, \mathrm{AT}$, and the simulated time trial on the track differed from the $10-\mathrm{km}$ race velocity.

Figures 2 to 4 show the agreement values established using the Bland-Altman plot, with values presented for the total group and stratified by gender for the estimated velocities in the CV and AT tests, mean velocity established in a simulated time trial on the track with the velocity of the $10-\mathrm{km}$ race.

As seen in Figures 2 to 4, comparisons using the Bland-Altman plot showed that all residual scores were within the range of agreement defined at \pm 1.96 standard deviation for comparisons between the $\mathrm{CV}, \mathrm{AT}$, and the simulated time trial on the track with the $10-\mathrm{km}$ race.

Table 3 presents the indicators of concordances, reproducibility, values of the errors of the comparisons of the velocities determined by the $\mathrm{CV}$, $\mathrm{AT}$, and the simulated time trial on the track with the $10-\mathrm{km}$ race velocity for the total group and stratified by gender.

As seen in Table 3, the CV delta analysis overestimated the velocity of the $10-\mathrm{km}$ race, while the deltas of the AT and simulated time trial on the track underestimated the $10-\mathrm{km}$ race velocity. The agreement and reproducibility between the velocities calculated by ICC and Cronbach's alpha presented high values and considered excellent for the $\mathrm{CV}$, the AT, and the simulated time trial on the track, according to the classification of the reference range established in $\geq 70$. Moreover, the total error and standard error estimate were mostly less than $1 \mathrm{~km} / \mathrm{h}$ for the CV and simulated time trial on the track, and close to $1.5 \mathrm{~km} / \mathrm{h}$ for the AT.

Figure 5 shows the delta percentage of the difference between the velocity determined by the

Table 1. Characterization of the sample $(N=34)$

\begin{tabular}{|c|c|c|c|}
\hline & Total group (34) & Males (20) & Females (14) \\
\hline Age (years) & $42.4 \pm 11.0$ & $41.4 \pm 12.7$ & $43.7 \pm 8.9$ \\
\hline Body weight (kg) & $65.7 \pm 9.0$ & $68.8 \pm 9.2$ & $61.1 \pm 7.0^{*}$ \\
\hline Body height (m) & $1.69 \pm 0.8$ & $1.72 \pm 0.8$ & $1.64 \pm 0.4^{*}$ \\
\hline BMI $\left(\mathrm{kg} / \mathrm{m}^{2}\right)$ & $25.8 \pm 6.5$ & $27.7 \pm 6.8$ & $23.1 \pm 5.4^{*}$ \\
\hline Body fat (\%) & $15.9 \pm 6.5$ & $10.7 \pm 4.8$ & $23.1 \pm 8.0^{*}$ \\
\hline $\mathrm{VO}_{2 \operatorname{MAX}}(\mathrm{ml} / \mathrm{kg} / \mathrm{min})$ & $49.5 \pm 8.1$ & $54.6 \pm 5.0$ & $42.2 \pm 6.3^{*}$ \\
\hline MHR (bpm) & $180.5 \pm 8.9$ & $180.3 \pm 10.6$ & $180.6 \pm 7.8$ \\
\hline $\mathrm{AT}_{\mathrm{VO} 2}(\mathrm{ml} / \mathrm{kg} / \mathrm{min})$ & $43.5 \pm 7.3$ & $47.9 \pm 3.6$ & $36.7 \pm 6.7^{*}$ \\
\hline $\mathrm{AT}_{\text {SPEED }}(\mathrm{km} / \mathrm{h})$ & $12.6 \pm 1.8$ & $13.7 \pm 1.2$ & $10.9 \pm 1.0^{*}$ \\
\hline $\mathrm{AT}_{\mathrm{HR}}(\mathrm{bpm})$ & $169.0 \pm 10.4$ & $169.3 \pm 12.0$ & $168.6 \pm 9.4$ \\
\hline $\mathrm{AT}_{\mathrm{RPE}}$ & $12.8 \pm 1.9$ & $12.5 \pm 1.8$ & $13.4 \pm 2.3$ \\
\hline Running 10 km (min) & $45.9 \pm 7.3$ & $41.5 \pm 4.3$ & $52.3 \pm 6.2^{*}$ \\
\hline
\end{tabular}

Note. BMI: body mass index; $\mathrm{VO}_{2 \mathrm{MAX}}$ : maximal oxygen uptake; MHR: maximum heart rate; $\mathrm{AT}$ : anaerobic threshold; $\mathrm{AT}_{\mathrm{VO} 2}$ : oxygen uptake at the AT; $A T_{\text {SPEED }}$ : speed at the AT; $A T_{H R}$ : heart rate at the AT; $A T_{\text {RPE: }}$ rating of perceived exertion at the $A T$. * Significant difference between males and females, $p<.05$.

Table 2. Mean and standard deviation of the determined speeds in the 10-km race, simulated on the track, at the CV and AT

\begin{tabular}{lccc}
\hline & Total group & Males & Females \\
\hline 10-km race & $13.4 \pm 2.1$ & $14.6 \pm 1.5$ & $11.6 \pm 1.3$ \\
CV $(n=34 / 20 / 14)$ & $13.9 \pm 2.2^{*}$ & $15.3 \pm 1.4^{*}$ & $11.9 \pm 1.6$ \\
$10-k m$ race & $13.4 \pm 2.1$ & $14.5 \pm 1.4$ & $11.6 \pm 1.3$ \\
AT $(n=33 / 19 / 14)$ & $12.6 \pm 1.76^{*}$ & $13.7 \pm 1.23^{*}$ & $11.2 \pm 1.3$ \\
$10-k m$ race & $13.5 \pm 2.1$ & $14.8 \pm 1.6$ & $12.1 \pm 1.7$ \\
Simulated on the track $(n=24 / 12 / 12)$ & $12.8 \pm 1.9^{*}$ & $14.0 \pm 1.5^{*}$ & $11.5 \pm 1.5^{*}$ \\
\hline
\end{tabular}

Note. CV: critical velocity; AT: anaerobic threshold. *Significant difference from 10-km race velocity, $\mathrm{p}<.05$. 

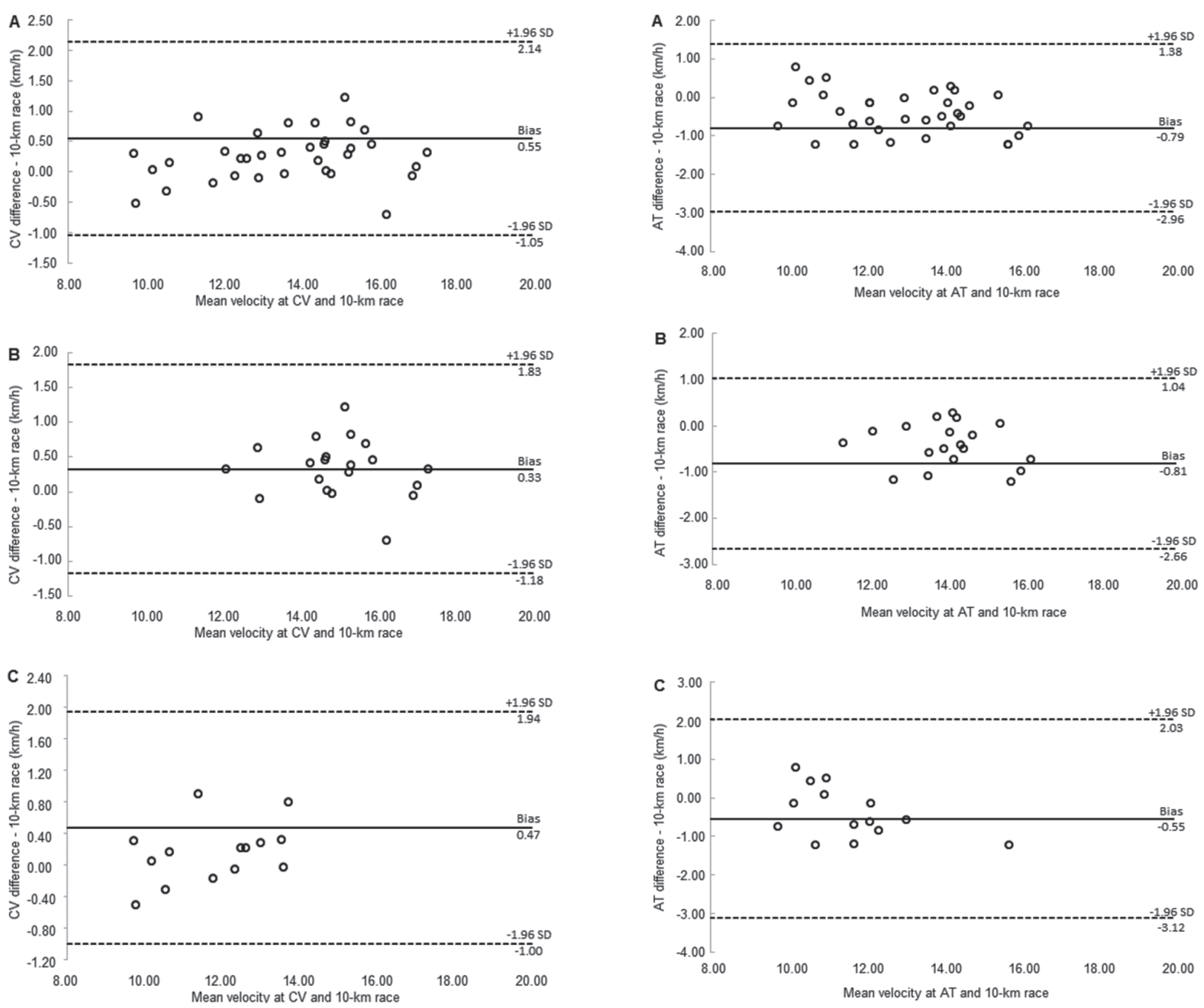

Figure 2. Agreement between the velocities estimated through the critical velocity test and the mean velocity of the $10-\mathrm{km}$ race. $A$-total group, $B$-males, and $C$-females.

Figure 3. Agreement between the velocities determined at the anaerobic threshold and the mean velocity of the 10-km race. $A$-total group, $B$-males, and $C$-females.

Table 3. Agreement coefficients, reproducibility, and error values of the speed comparisons determined by the CV, AT and simulated time trial on the track with the running $10 \mathrm{~km}$

\begin{tabular}{lccc}
\hline & Total group & Males & Females \\
\hline Critical velocity & $\mathrm{n}=34$ & $\mathrm{n}=20$ & $\mathrm{n}=14$ \\
Delta CV vs 10-km race $(\mathrm{km} / \mathrm{h})$ & 0.55 & 0.70 & 0.33 \\
ICC & $0.93(0.86-0.96)$ & $0.83(0.92-0.93)$ & $0.87(0.64-0.96)$ \\
Cronbach's alpha & 0.96 & 0.91 & 0.93 \\
Correlation & 0.93 & 0.83 & 0.88 \\
TE/SEE & $0.97 / 0.29$ & $1.07 / 0.45$ & $0.81 / 0.27$ \\
\hline Anaerobic threshold & $\mathrm{n}=33$ & $\mathrm{n}=19$ & $\mathrm{n}=14$ \\
Delta AT vs 10-km race $(\mathrm{km} / \mathrm{h})$ & -0.79 & -0.81 & -0.73 \\
ICC & $0.84(0.70-0.91)$ & $0.75(0.47-0.90)$ & $0.68(0.26-0.89)$ \\
Cronbach's alpha & 0.91 & 0.86 & 0.81 \\
Correlation & 0.85 & 0.76 & 0.73 \\
TE/SEE & $1.35 / 0.58$ & $1.23 / 0.60$ & $1.49 / 0.88$ \\
\hline Simulated time trial on the track & $\mathrm{n}=24$ & $\mathrm{n}=12$ & $\mathrm{n}=12$ \\
Delta simulated on the track vs 10-km race $(\mathrm{km} / \mathrm{h})$ & -0.67 & -0.74 & -0.60 \\
ICC & $0.96(0.91-0.98)$ & $0.94(0.80-0.98)$ & $0.93(0.78-0.98)$ \\
Cronbach's alpha & 0.98 & 0.97 & 0.97 \\
Correlation & 0.97 & 0.94 & 0.95 \\
TE/SEE & $0.87 / 0.14$ & $0.91 / 0.18$ & $0.82 / 0.18$ \\
\hline
\end{tabular}

Note. CV: critical velocity; ICC: intraclass correlation coefficient; TE: total error; SEE: standard error of estimation. ${ }^{*} \mathrm{p}<.05$. 

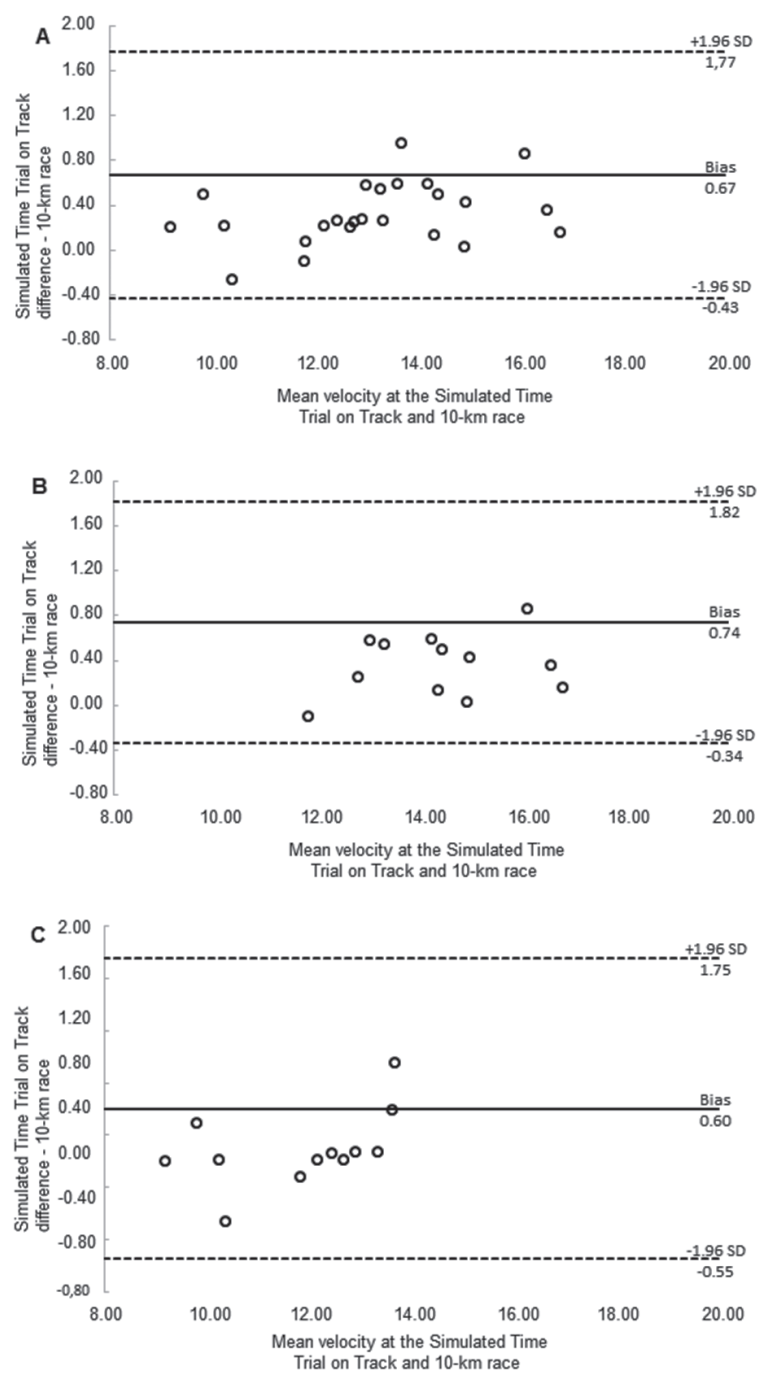

Figure 4. Agreement between the mean velocities established in a simulated time trial on the track and in a $10-\mathrm{km}$ race. A - total group, $B$-males, and $C$-females.

$\mathrm{CV}$, the $\mathrm{AT}$, and the simulated time trial on the track and the $10-\mathrm{km}$ race velocity.

As shown in Figure 5, the percentage difference showed that the CV presented the lowest delta in relation to the velocity of the $10-\mathrm{km}$ race, with $2.6 \%$ for women and $4.8 \%$ for men, both overestimating the velocity of the $10-\mathrm{km}$ race. On the other hand, both the simulated time trial on the track and the $\mathrm{CV}$ showed a tendency to underestimate the velocity of the $10-\mathrm{km}$ race (between 5.0 and $6.0 \%$, respectively).

\section{Discussion and conclusion}

The main results of the present study showed good agreement and reproducibility between the velocities determined by the CV, AT, and simulated time trial on the track with the real-time of a 10-km official race. These results corroborate the findings of another study (Souza, et al., 2014), which analyzed the predictive capacity of the AT determined in the laboratory and Montreal Test (MT) (Léger \& Boucher, 1980) for performance

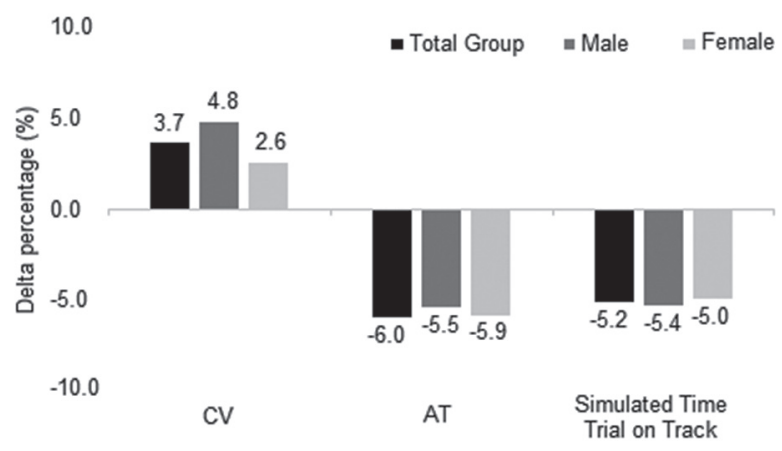

Figure 5. Delta percentage of the difference between the velocities determined by the $C V, A T$ and simulated time trial on the track, and the 10-km race.

at distances of $1.5,5.0$ and $10.0 \mathrm{~km}$. The authors found that performance prediction from the AT determined in both protocols (laboratory and MT) was dependent on the running distance. Also, physiological indexes obtained in a laboratory test that was able to predict performance in the $1.500 \mathrm{~m}$, $5.000 \mathrm{~m}$ and $10.000 \mathrm{~m}$ tests were similar to indexes obtained in MT, and indexes derived from MT had higher ability to predict performance than indexes derived from laboratory tests in the three distances analyzed.

Our results also partially corroborate the findings of another study (Santos, et al., 2012) that associated $\mathrm{VO}_{2 \mathrm{MAX}}$, the velocity at which $\mathrm{VO}_{2 \mathrm{MAX}}$ and $\mathrm{CV}$ were achieved with the performance in the $3.6-\mathrm{km}$ ascending race, $10 \mathrm{~km}$ and $21 \mathrm{~km}$ in men and women. The authors found that $\mathrm{CV}$ presented high and significant association with all the distances studied, proving to be an adequate predictor of aerobic performance. However, they pointed out that the indirectly estimated $\mathrm{VO}_{2 \mathrm{MAX}}$ was the variable with the best association with race performance in the $10-\mathrm{km}$ and $21-\mathrm{km}$ races. In the present study, our focus was on the comparison of velocities determined by field and laboratory methods, although we verified the association between $\mathrm{VO}_{2 \mathrm{MAX}}$ and the actual running speed in the $10-\mathrm{km}$ race. Here, our results diverge from previously reported study, since the highest correlations were found between the official running speed of $10 \mathrm{~km}$ and the $\mathrm{CV}(\mathrm{R}=.93)$ and the simulated time trial on the track $(\mathrm{R}=.97)$ to the detriment of comparisons with $\mathrm{VO}_{2 \mathrm{MAX}}(\mathrm{R}=.88)$ and the velocity at which $\mathrm{VO}_{2 \mathrm{MAX}}$ was reached $(\mathrm{R}=.89)$. On the other hand, we believe that these divergences cannot be understood by the simple metrical comparison of Pearson's linear correlation, nor used to indicate greater or less predictive or explanatory capacity. Although correlation is a strong indicator of association between two variables, in this case, there is a certain limitation, since the units and magnitudes of the measurements are different, therefore, it is not possible to use tests that measure the comparison between the means, its variance and error size. 
The CV, when compared to the velocity established by the AT and the simulated time trial on the track, showed the lowest absolute and delta percentages, the highest CCI and Cronbach's alpha, as well as the lowest SEE concerning the time of a $10-\mathrm{km}$ official race. Also, the paired $t$-test showed that the velocities determined by the $\mathrm{CV}$ and $\mathrm{AT}$ were similar to the time of the $10-\mathrm{km}$ race in women, showing that the CV and AT for females already presented themselves as good predictors of running speed in a $10-\mathrm{km}$ race. However, in studies of this nature, we cannot rule out or accept the viability of an instrument only by the absence or presence of significant difference established through the paired t-test, since other important tests and calculations are needed that can help establish the instrument's possible agreement and reproducibility as well as greater credibility. In the present study, comparisons using the Bland-Altman plot showed that all residual scores were within the range of agreement. Moreover, the agreement and reproducibility between the velocities calculated by CCI and Cronbach's alpha were considered excellent for the $\mathrm{CV}$, AT and the simulated time trial on the track, according to the classification of reference established in the literature (Fleiss, 1999). Furthermore, the absolute and percent delta values, as well as the total error and standard error of estimate were considered low in the present study. The results also showed that the CV presented the smallest delta percentage in relation to the running speed of the $10-\mathrm{km}$ race, overestimating the running speed of the $10-\mathrm{km}$ race by $2.6 \%$ for women and by $4.8 \%$ for men. Alternatively, the simulated time trial on the track and the AT underestimated the running speed of the $10-\mathrm{km}$ race by between $5.0 \%$ and $6.0 \%$, respectively. Finally, the total error and standard error of estimate were mostly less than $1 \mathrm{~km} / \mathrm{h}$ for the CV and the simulated time trial on the track and close to $1.5 \mathrm{~km} / \mathrm{h}$ for the AT, which allows us to infer that the velocities determined through the $\mathrm{CV}$, AT and simulated time trial on the track showed good reproducibility and agreement about the running speed of $10-\mathrm{km}$ race.

Demonstrating the predictive capacity of $\mathrm{CV}$ with other important variables such as aerobic performance (Hughson, Orok, \& Staudt, 1984; Kranenburg \& Smith, 1996), lactate and ventilatory thresholds (Moritani, Nagata, Devries, \& Muro, 1981; Smith \& Jones, 2001; Wakayoshi, et al., 1992, 1992), swimming (Garatachea, et al., 2006; Wakayoshi, et al., 1992) and cycling (Hiyane,
Simões, Sílvia, \& Campbell, 2006) performance is not new in literature. Another study evaluated the validity of the $\mathrm{CV}$ for determining the effects of training on the anaerobic threshold in endurance runners and confirmed that the $\mathrm{CV}$ had good validity for the determination of the AT before, but not after a four-week training program (Denadai, et al., 2003). The authors report that there was a loss of sensitivity between the AT and the CV to identify the adaptations induced by the training, justifying that the mechanisms that determined the adaptations in lactate responses and the CV may not be the same (Denadai, et al., 2003). This difference in pre- and post-training moments can be explained by the principle of biological individuality, since the adaptations acquired through training may be different depending on individual aspects such as age, gender, rest time, genetic aspects, and food, among others.

Thus, the extrapolation of the results of the present study should be applied with caution throughout a training program. Although the velocities determined by the CV, AT and the simulated time trial on the track showed good applicability and are useful tools for physiologists and endurance runners' coaches in determining the pace, race strategy and choice of training intensities throughout the periodization, their use should be one of the variables used as a parameter for the training and the race strategy, since other equally important variables should be considered. Also, both the $\mathrm{CV}$ and the simulated time trial on the track can be used as a low-cost, easy-to-apply, and reliable tool for use in endurance runners.

The limitation of the present study was the nonperformance of all the tests at the same time of day. However, the distribution of the tests was randomized, except for the race and the $10-\mathrm{km}$ simulated time trial. Besides, there were no great climatic variations during the tests. Another limitation is the impossibility of ensuring that the athletes complied with the recommendation not to perform vigorous exercises 48 hours before each experiment, though, messages were sent and phone calls were made to the athletes remembering the need to follow the recommendations before the tests.

We concluded the measurement of the $\mathrm{CV}$ determined on the track with only two distances (400 $\mathrm{m}$ and 2,000 m), the AT determined in laboratory conditions and the simulated time trial on the track were valid to estimate running speed in a $10-\mathrm{km}$ race, once a good agreement was observed. 


\section{References}

Anthony, D., Rüst, C.A., Cribari, M., Rosemann, T., Lepers, R., \& Knechtle, B. (2014). Differences in participation and performance trends in age group half and full marathoners. The Chinese Journal of Physiology, 57(4), $209-219$. doi: 10.4077/CJP.2014.BAC219

Bertuzzi, R., Lima-Silva, A.E., Pires, F.O., Damasceno, M.V., Bueno, S., Pasqua, L.A., \& Bishop, D.J. (2014). Pacing strategy determinants during a $10-\mathrm{km}$ running time trial: Contributions of perceived effort, physiological, and muscular parameters. Journal of Strength and Conditioning Research, 28, 1688-1696. doi: 10.1519/ JSC.0000000000000314

da Silva, D.F., Sotero, R.C., Simões, H.G., \& Machado, F.A. (2015). Maximal aerobic speed calculated by heart rate cost: Relationship with performance. Revista Andaluza de Medicina Del Deporte, 8(1), 7-15.doi: 10.1016/j. ramd.2014.06.001

Denadai, B.S., Ortiz, M.J., Stella, S., \& Mello, M.T. (2003). Validity of the critical velocity for determination of the training effects on the anaerobic threshold in endurance runners. Revista Portuguesa de Ciências do Desporto, 3(1), 16-23. doi: 10.5628/rpcd.03.01.16

Faude, O., Kindermann, W., \& Meyer, T. (2009). Lactate threshold concepts: How valid are they? Sports Medicine, $39,469-490$.

Ferreira, A.P., Ferreira, C.B., Brito, C.J., Souza, V.C., Córdova, C., Nóbrega, O.T., \& França, N.M. (2013). The effect of aerobic exercise intensity on attenuation of postprandial lipemia is dependent on apolipoprotein E genotype. Atherosclerosis, 229(1), 139-144. doi: 10.1016/j.atherosclerosis.2013.03.027

Fleiss, J.L. (1999). Design and analysis of clinical experiments. Willey.

Garatachea, N., Abadía, O., García-Isla, F.J., Sarasa, F.J., Bresciani, G., González-Gallego, J., \& De Paz, J.A. (2006). Determination and validity of critical swimming velocity in elite physically disabled swimmers. Disability and Rehabilitation, 28(24), 1551-1556. doi: 10.1080/09638280600646318

Gómez-Molina, J., Ogueta-Alday, A., Camara, J., Stickley, C., Rodríguez-Marroyo, J.A., \& García-López, J. (2017). Predictive variables of half-marathon performance for male runners. Journal of Sports Science and Medicine, 16(2), 187-194.

Hiyane, W.C., Simões, H.G., Sílvia, C., \& Campbell, G. (2006). Critical velocity as a noninvasive method to estimate the lactate minimum velocity on cycling. Revista Brasileira de Medicina do Esporte, 12(6), 340-344.

Hughson, R., Orok, C., \& Staudt, L. (1984). A high velocity running test to assess endurance running potential. International Journal of Sports Medicine, 5(1), 23-25.

Knechtle, B., Nikolaidis, P.T., Zingg, M.A., Rosemann, T., \& Rüst, C.A. (2016). Half-marathoners are younger and slower than marathoners. SpringerPlus, 5(1), 1-16. doi: 10.1186/s40064-016-1704-9

Kranenburg, K.J., \& Smith, D.J. (1996). Comparison of critical speed determined from track running and treadmill tests in elite runners. Medicine and Science in Sports and Exercise, 28(5), 614-618.

Léger, L.A., \& Boucher, R. (1980). An indirect continuous running multistage field test: The Université de Montréal track test. Canadian Journal of Applied Sport Sciences, 5(2), 77-84.

Lima-Silva, A.E., Bertuzzi, R.C.M., Pires, F.O., Barros, R.V., Gagliardi, J.F., Hammond, J., ..., \& Bishop, D.J. (2010). Effect of performance level on pacing strategy during a 10-km running race. European Journal of Applied Physiology, 108(5), 1045-1053. doi: 10.1007/s00421-009-1300-6

Moritani, T., Nagata, A., Devries, H.A., \& Muro, M. (1981). Critical power as a measure of physical work capacity and anaerobic threshold. Ergonomics, 24(5), 339-350. doi: 10.1080/00140138108924856

Ogueta-Alday, A., \& Gácia-López, J. (2015). Factors affecting long-distance running performance. RICYDE: Revista Internacional de Ciencias del Deporte, 11(41), 226-244. doi: 10.5232/ricyde

Santos, M.A.M. dos, Costa, M. da C., Brito-Gomes, J.L. de, Perrier-Melo, R.J., Oliveira, S.F.M. de, \& Farah, B.Q. (2017). Associated factor at performance in race of 10.000 meter by amateurs runners. Journal of Physical Education, 28(1), 1-10. doi: 10.4025/jphyseduc.v28i1.2836

Santos, T.M., Rodrigues, A.I., Greco, C.C., Marques, A.L., Terra, B.S., \& Oliveira, B.R.R. (2012). Estimated VO 2max and its corresponding velocity predict performance of amateur runners. Brazilian Journal of Kinanthropometry and Human Performance, 14(2), 192-201. doi: 10.1590/1980-0037.2012v14n2p192

Smith, C.G.M., \& Jones, A.M. (2001). The relationship between critical velocity, maximal lactate steady-state velocity and lactate turnpoint velocity in runners. European Journal of Applied Physiology, 85(1-2), 19-26. doi: 10.1007/ s004210100384

Souza, K.M. de, Lucas, R.D. de, Grossl, T., Costa, V.P., Guilherme, L., \& Guglielmo, A. (2014). Performance prediction of endurance runners through laboratory and track tests. Brazilian Journal of Kinanthropometry and Human Performance, 16(4), 465-474. https://doi.org/10.5007/1980-0037.2014v16n4p465

Souza, K.M. de, Vieira, G., Baldi, M.F., Guglielmo, L.G.A., Lucas, R.D. de, \& Denadai, B.S. (2011). Physiological and neuromuscular variables associated to aerobic performance in endurance runners: Effects of the event distance. Revista Brasileira de Medicina do Esporte, 17(1), 40-44. doi: 10.1590/S1517-86922011000100008

Thiel, C., Foster, C., Banzer, W., \& de Koning, J. (2012). Pacing in Olympic track races: Competitive tactics versus best performance strategy. Journal of Sports Sciences, 30(11), 1107-1115. doi: 10.1080/02640414.2012.701759 
Wakayoshi, K., Ikuta, K., Yoshida, T., Udo, M., Moritani, T., Mutoh, Y., \& Miyashita, M. (1992). Determination and validity of critical velocity as an index of swimming performance in the competitive swimmer. European Journal of Applied Physiology and Occupational Physiology, 64(2), 153-157. doi: 10.1007/BF00717953

Wakayoshi, K., Yoshida, T., Udo, M., Kasai, T., Moritani, T., Mutoh, Y., \& Miyashita, M. (1992). A simple method for determining critical speed as swimming fatigue threshold in competitive swimming. International Journal of Sports Medicine, 13(05), 367-371. doi: 10.1055/s-2007-1021282

Submitted: August 10, 2018

Accepted: June 19, 2020

Published Online First: December 17, 2020

Correspondence to:

Aparecido Pimentel Ferreira, Ph.D.

Phone: +556135749950

Address: QS 05 Rua 300 Lote 01

71735-513, Federal District, Brazil

E-mail: cidopimentel@gmail.com 